\title{
Ensino de Ciências por Investigação: Uma Estratégia Didática para Auxiliar a Prática dos Professores dos Anos Iniciais do Ensino
}

\section{Fundamental}

Alexandre Rodrigues da Conceição*, Rosemeire da Silva Dantas Oliveira*, Elton Casado Fireman**

\section{Resumo}

Ensinar Ciências para que os estudantes tenham condições de (re)construir sua compreensão sobre o mundo que o cerca por meio da linguagem da Ciência requer do professor uma reflexão sobre as estratégias didáticas utilizadas para essa finalidade. Nesse contexto, destacamos as potencialidades que o Ensino por Investigação pode assumir diante dessa necessidade educacional. Sendo assim, desenvolvemos uma Sequência de Ensino Investigativa (SEI) para trabalhar dois conteúdos de Botânica a fim de investigarmos as contribuições dessa estratégia didática para aprendizagem de professores dos anos iniciais do Ensino Fundamental que estão em formação inicial. Este estudo teve por objetivos: verificar como se deu o processo de aprendizagem dos participantes diante da aplicação da SEl; identificar quais as sugestões destes futuros docentes para sua adaptação e melhoramento e; descrever quais as potencialidades desta estratégia didática para trabalhar conteúdos de natureza biológica. A pesquisa foi desenvolvida na disciplina de Saberes e Metodologia do Ensino de Ciências II. Essa disciplina faz parte da matriz curricular do curso de Licenciatura em Pedagogia da Universidade Federal de Alagoas. Desta forma, esta pesquisa possui uma abordagem qualitativa, onde buscamos analisar os diálogos registrados por meio da gravação em áudio. Nesse contexto, optamos por realizar análise textual discursiva. Como resultados, constatamos que os professores em formação inicial apresentam dificuldades em fornecer explicações baseadas no conhecimento cientifico.

\footnotetext{
Mestrando em Educação na Universidade Federal de Alagoas e Licenciado em Ciências Biologias na (UFAL). Bolsista da Fundação de Amparo à Pesquisa do Estado de Alagoas (FAPEAL), Brasil. E-mail: allexandrebcp@ hotmail.com

* Doutoranda em Educação na Universidade Federal de Alagoas. Licenciada em Pedagogia e Mestra em Educação (UFRN). Bolsista da Coordenação de Aperfeiçoamento de Pessoal de Nível Superior (CAPES), Brasil. E-mail: rosemeire.dantas.oliveira@gmail.com

*** Professor da Universidade Federal de Alagoas, atuando nos Programas de Pós-Graduação em Educação e de Ensino de Ciências e Matemática. Líder do grupo de pesquisa Formação de Professores e Ensino de Ciências. Brasil. E-mail: elton@cedu.ufal.br
}

Recebido em: 13/12/2019 - Aceito em: 12/02/2020

https://doi.org/10.5335/rbecm.v3i1.10400

http://creativecommons.org/licenses/by-nc-nd/4.0 
Percebemos também que a utilização da SEI consegue tornar a sala de aula um ambiente dialógico, de descobertas e reconstrução de um conhecimento já existente se configurando como uma importante estratégia didática para trabalhar o conhecimento científico em todos os níveis de ensino.

Palavras-chave: Formação Inicial Docente. Ensino de Ciências. Estratégia Didática. Conteúdos de Botânica.

\section{Introdução}

Ensinar Ciências, para além da exposição dos conteúdos e uso exclusivo do livro didático enquanto únicos recursos pedagógicos capazes de auxiliar a prática docente, requer do professor uma reformulação da concepção do que é, para que e porque ensinar Ciências nos anos iniciais do Ensino Fundamental, já que as aulas que almejam apropriação do conhecimento apenas pela memorização podem dificultar a aprendizagem do conhecimento científico.

O cenário passa a se tornar ainda mais complexo ao se verificar o processo formativo dos professores dos anos iniciais, pois não é incomum encontrarmos na literatura pesquisas que apontem como principal fragilidade presente nas instituições formadoras, a carga horária insuficiente para trabalhar os conhecimentos de Ciências da Natureza (DUCATTI-SILVA, 2005; BIZZO, 2009; GATTI; BARRETO, 2009; PIRES; MALACARNE, 2016; GALIAN; ARROIO; SASSERON, 2013). Desta forma, torna-se fundamental que os futuros professores passem a ter conhecimentos sobre as possibilidades de ensinar Ciências se aproximando da forma como o conhecimento científico é construído. E diante das dificuldades apresentadas pelos estudantes durante a Educação Básica com os conteúdos de Botânica, sendo estas dificuldades um reflexo da forma como o ensino das plantas vem sendo trabalhado (HOEHNE, 1937), baseado apenas na exposição, memorização, repetição e distante da realidade dos discentes (KINOSHITA et al., 2006), buscamos, neste estudo, responder ao seguinte questionamento: Quais as contribuições de uma Sequência de Ensino Investigativa para aprendizagem em conteúdos de Botânica em um Curso de Pedagogia?

Partindo do pressuposto de que a formação inicial reflete na prática cotidiana do professor (OVIGLI; BERTUCCI, 2009),esta pesquisa possui como objetivos investigar a contribuição da Sequência de Ensino Investigativa (SEI) para a aprendizagem dos conteúdos de Botânica; identificar quais as sugestões destes futuros docentes 
para sua adaptação e melhoramento e descrever quais as potencialidades desta estratégia didática para trabalhar conteúdos de natureza biológica.

Esta pesquisa foi desenvolvida na disciplina de Saberes e Metodologia do Ensino de Ciências II (SMEC II), no segundo semestre de 2018. A disciplina faz parte da matriz curricular do oitavo período do curso de Licenciatura em Pedagogia da Universidade Federal de Alagoas (UFAL). Para realização da pesquisa, optou-se por uma abordagem qualitativa (MINAYO, 2002), buscando compreender como se deu o aprendizado dos Licenciandos em Pedagogia diante da aplicação da SEI. Como fonte de dados, foram analisados os diálogos estabelecidos durante o desenvolvimento da SEI registrados por meio de um dispositivo de gravação de áudio. Nesse Contexto, optou-se pela transcrição dos áudios e realização da análise textual discursiva (MORAES, 2003; MORAES; GALIAZZI, 2016).

Buscando preservar a identidade dos participantes da pesquisa, os diálogos serão representados pelos turnos no qual ocorreu a aplicação da SEI, bem como um dos registros gráficos feito pelos estudantes. Assim, para situar o leitor sobre a organização desta pesquisa, na primeira seção realizar-se-á a integração entre a discussão sobre formação dos professores dos anos inicias do Ensino Fundamental para o ensino de Ciências, procurando destacar o caso da UFAL onde a pesquisa foi realizada. Posteriormente, aborda-se o Ensino de Ciências por Investigação (ECI) como uma estratégia didática que possui potencialidade para desenvolver de forma processual a Alfabetização Científica. Em seguida, destaca-se os desafios encontrados no ensino de Botânica e apresentaremos uma proposta para trabalhar dois conteúdos de Botânica por meio da perspectiva do Ensino por Investigação. Segue-se pelo percurso metodológico e dos resultados e discussão que foram divididos em primeiro e segundo momento. Por fim, apresentaremos nossas considerações finais destacando a relevância do Ensino por Investigação como uma importante estratégia didática para ensinar Ciências nos anos iniciais do Ensino Fundamental.

\section{A formação de professores dos anos iniciais para o ensino de ciências e o caso da ufal}

Ensinar Ciências de maneira que os estudantes possam entender os fatos e fenômenos que os cercam diariamente e tenham condições de compreender as implicações da Ciência na sociedade, tem se tornado uma necessidade vigente no ensino 
desta área do conhecimento (CHASSOT, 2018). Para isso, torna-se necessário que o ensino de Ciências seja trabalhado para alcançar esses objetivos e tenha condições de propiciar aos discentes, o quanto antes, uma educação científica de qualidade.

Se para Ovigli e Bertucci (2009) há uma relação intrínseca entre o processo formativo dos professores responsáveis pelos anos iniciais do Ensino Fundamental e sua prática, devemos voltar nossa atenção para a forma como o ensino de Ciências está presente na formação dos pedagogos. Uma vez que para os autores a relação entre a formação e atuação tem demonstrado fragilidades no ensino de Ciências.

De acordo com as Diretrizes Curriculares Nacionais para a Formação Inicial em Nível Superior e para a Formação Continuada (DCN), no artigo 5, os professores após a conclusão do curso deverão estar aptos para atender uma série de demandas garantindo a aprendizagem e o desenvolvimento dos estudantes durante o percurso educacional (Parecer CNE/CP 2 de 2015, 2015). Contudo, pesquisas sobre a formação dos professores para ensinar Ciências nos anos iniciais do Ensino Fundamental (AUGUSTO; AMARAL, 2015; GALIAN; ARROIO; SASSERON,2013; SOUZA; CHAPANI, 2015) demonstram preocupações com a carga horária insuficiente presente nos Cursos de Pedagogia para aprendizagem de Ciências, que têm culminado na falta de apropriação dos conhecimentos científicos.

De acordo com as DCN (Parecer CNE/CP 2 de 2015, 2015), os cursos de formação inicial de professores para a Educação Básica em nível superior dispõem de uma carga horária mínima de 3.200 horas, sendo distribuídas de forma a contemplar as necessidades formativas dos futuros professores. Na UFAL, o curso de Pedagogia do campus Maceió dispõe de 3.500 horas. Porém, mesmo que a quantidade de horas pareça ser significativa, a distribuição desta carga horária para contemplar o ensino de Ciências tem movido discussões como as apontadas por Bizzo (2002), ao destacar que os professores polivalentes, na maioria das vezes, possuem uma carência na apropriação não apenas do conhecimento científico, mas também das metodologias que são próprias da Ciência.

Na UFAL, no turno diurno, as disciplinas destinadas a trabalhar com o ensino de Ciências são intituladas de Saberes e Metodologias do Ensino de Ciências I e II. A disciplina Saberes e Metodologias do Ensino de Ciências I compõe o conjunto de disciplinas do sétimo período com carga horária de $60 \mathrm{~h}$. Destas, $40 \mathrm{~h}$ são destinadas à teoria e $20 \mathrm{~h}$ à prática. Já a disciplina de Saberes e Metodologias do Ensino de Ciências Naturais II faz parte do conjunto de disciplina do oitavo período, seguindo 
a mesma divisão de carga horária, o que representa apenas $3,4 \%$ da carga horária total do curso.

No turno noturno a disciplina de Saberes e Metodologias do Ensino de Ciências Naturais I também é ofertada no sétimo período, com a carga horária total de $60 \mathrm{~h}$. Há, no entanto, um decréscimo da quantidade de horas destinadas às atividades práticas, sendo apenas $10 \mathrm{~h}$. As aulas teóricas ocupam a maior parte - 50h; Enquanto que no oitavo período a disciplina de SMEC II possui a carga horária dividida em $40 \mathrm{~h}$ destinadas à teoria e $20 \mathrm{~h}$ à prática.

Se para Carvalho e Gil-Pérez (2011) o professor deve ter domínio da matéria a ser ensinada, o professor dos anos iniciais, nesse contexto, provavelmente apresentará dificuldades em criar aulas que desenvolvam habilidades nos estudantes que são importantes para sua atuação na sociedade, já que durante sua formação o tempo destinado à compreensão do por que, para que e como ensinar Ciências ainda é insuficiente.

Tal situação tem levado alguns pesquisadores (DUCATTI-SILVA, 2005; BONANDO, 1994; LONGHINI, 2016, ZANON, 2005, ROCHA, 2013; SANTANA, SILVEIRA, 2018) a constatarem que a formação de professores para ensinar Ciências nos anos iniciais ainda é precária, o que tem contribuído para um ensino superficial, reduzindo a ação docente à exposição dos conteúdos e à utilização excessiva do livro didático, sendo necessário, pois, que se reveja o projeto pedagógico dos cursos formadores.

\section{Ensino de ciências por investigação como uma estratégia didática para alfabetização científica}

O Ensino de Ciências por Investigação é destacado na literatura do ensino de Ciências como uma estratégia didática que possui potencialidade para trabalhar o conhecimento científico na sala de aula, e tem como um dos objetivos tornar a sala de aula um ambiente investigativo e promover o pensamento crítico (CARVALHO, 2013; BOSZKO, GÜLLICH, 2019). Entre as diferentes modalidades didáticas para o ensino de Ciências e Biologia apontadas por Krasilchik (2004), buscamos destacar o ECI como mais uma estratégia didática, sendo necessário que passemos a compreender a natureza de cada Ciência e assim possamos planejar o ensino para alcançar os objetivos estabelecidos. O planejamento da SEI, de acordo com os pres- 
supostos teóricos, contribui para que alcancemos resultados favoráveis na execução das atividades que a compõe.

De acordo com Carvalho (2013) uma SEI é composta por um conjunto de atividades que são fundamentais, que ao serem bem planejadas e executadas proporcionam aos professores e estudantes melhorias no processo de ensino e aprendizagem em Ciências. Carvalho (2011) destaca que essas melhorais podem ser observadas pelo fato da SEI contemplar "a participação ativa dos estudantes, a interação aluno-aluno, a passagem da linguagem cotidiana para a linguagem científica etc” (p. 257).

Torna-se importante destacarmos que a utilização de uma SEI em conteúdos que envolvam Ciências Biológicas devem atender a forma como a construção do conhecimento ocorre nesta área do conhecimento. Diferente da Física, na Biologia “as atividades experimentais são de difícil implementação" (TRIVALETO; TONIDANDEL, 2015, p. 99). Isso se deve ao fato de que a Biologia trata de organismos vivos que possuem um tempo maior de resposta a um estímulo que pode variar sob as mesmas condições. Na Biologia, segundo Scarpa e Silva (2013, p. 137), “o método observacional-comparativo é extremamente importante no fornecimento de hipóteses e resposta para muitos problemas biológicos”. As autoras corroboram com o que é argumentado por Mayr (1998) ao esclarecer que na Biologia a observação foi responsável pela construção de boa parte do conhecimento nesta área.

Assim, a inserção do Ensino de Ciências por Investigação precisa ser planejada de acordo com a natureza de cada Ciência, criando momentos em que os estudantes possam levar e testar suas hipóteses, argumentar, construir conhecimento a partir da relação com o outro, além de desenvolver a leitura e a escrita. $\mathrm{O}$ desenvolvimento dessas habilidades pode levar os estudantes a alcançarem um objetivo importante no ensino de Ciências que é Alfabetização Científica, pois serão capazes de compreender informações científicas, tendo a capacidade de tomar decisões que possam implicar em um bem-estar pessoal e social (CARVALHO, 2013). Para Chassot (2018) uma pessoa alfabetizada cientificamente possui um conjunto de conhecimentos que fornecem condições de fazer uma leitura do mundo ao seu redor, tendo a possibilidade de serem sujeitos transformadores da realidade.

Nesse contexto, enfatizamos a importância de ampliarmos o contato desde cedo dos estudantes aos conhecimentos que envolvem o ensino de Ciências, para que, de forma processual, possam desenvolver a Alfabetização Científica, pois como bem apontado por Lorenzetti e Delizoicov (2001) esse processo deve acontecer durante 
toda a vida. Para que esse contexto possa fazer parte do ensino de Ciências desde os anos iniciais do Ensino Fundamental, o ECI com vistas à Alfabetização Científica precisa fazer parte da formação do futuro professor dos anos iniciais.

Autores como Lima e Maués (2006) e Souza e Chapani (2015) defendem um processo formativo para os professores dos anos iniciais do Ensino Fundamental onde se faça presente o Ensino por Investigação, para que os docentes compreendam a importância da inserção de estratégias didáticas que são próprias das Ciências da Natureza e que contribuem para a construção do conhecimento científico.

\section{Ensino de botânica: quanto antes melhor}

O interesse em aprender sobre as plantas deveria ser uma condição natural, já que esses organismos vivos estão presentes ao longo da história da humanidade. Contudo, o cenário do ensino de Botânica tem demonstrado que o interesse pelas plantas está cada vez mais em declínio. Ao recorrermos à literatura, deparamo-nos com uma série de fatores que podem estar relacionados à essa falta de interesse. Para Martins e Braga (1999) um dos motivos diz respeito ao fato dos professores priorizarem outros ramos da Biologia, já para Santos e Seccatini (2004), os professores de Ciências e Biologia demonstram insegurança para trabalhar esses conteúdos. Já um terceiro motivo, como apresentado por Güllich (2014) demonstra a dificuldade dos docentes em utilizar metodologias que consigam despertar o interesse dos estudantes.

São inúmeros os empecilhos encontrados no ensino de Botânica que precisam ser superados, Ursi et al. (2018, p. 16) argumenta que para usufruirmos de um ensino de Botânica de qualidade será necessário

[...] atividades práticas, contextualização ao cotidiano, atividade de extensão: Universidade-Escola, utilização de tecnologias, abordagem sobre ética e cidadania, enfoque evolutivo, contextualização por meio da cultura e melhoria na formação e valorização docente.

Sendo assim, planejar o ensino de Botânica de acordo com essas necessidades se torna um importante caminho pedagógico a ser percorrido, buscando promover um processo de ensino e aprendizagem onde os estudantes tenham não apenas a capacidade de reconhecer a importância das plantas, mas que possam desenvolver atitudes de cuidados e preservação do meio ambiente. 
Configurando o quadro de dificuldades no ensino de Botânica, Kinoshita et al. (2006) estabelece outras fragilidades, dentre elas estão o excesso de teoria, a incapacidade de despertar o interesse dos estudantes, a escolha de outras áreas, o ensino baseado na repetição e não na reflexão etc. A junção dessas dificuldades apresentadas até aqui nos leva ao desenvolvimento de uma característica estabelecida por Wandersee e Schussler (2001) como cegueira Botânica. Esse termo foi estabelecido para caracterizar a nossa incapacidade de perceber as plantas ao nosso redor. Entre as explicações existentes para essa condição que não ocorre de forma proposital, Hoehne (1937) destaca que o ensino precário pode ser uma das causas que têm diminuído o interesse pelas plantas. Embora desde os Parâmetros Curriculares Nacionais (PCN) as plantas façam parte dos conteúdos a serem ensinados desde os anos iniciais (BRASIL, 1997), a situação passa a ter um agravante ainda maior, isso porque a Base Nacional Comum Curricular em suas propostas preza pela extinção do ensino das plantas (BRASIL, 2018).

Verifica-se, portanto, ao voltarmos nossa atenção para o espaço ocupado pelos conteúdos sobre as plantas nos anos iniciais, na unidade temática vida e evolução, que em cinco anos de formação os estudantes têm contato com esses conteúdos apenas no segundo ano (BRASIL, 2017). Ursi et al. (2018, p. 12) chama atenção para a necessidade de "promovermos um movimento de resistência e valorização das plantas e de seu ensino". Essa resistência consiste na inserção do ensino de Botânica ao longo do processo de escolarização dos estudantes, para que compreendam as plantas não apenas como seres estáticos, sem funções ou importância.

\section{Metodologia}

\section{Desenvolvimento da pesquisa}

Para realização dessa pesquisa optamos por uma abordagem qualitativa que segundo Moraes (2003) é um tipo de investigação que vem sendo utilizada com frequência quando o objetivo é a realização de análises textuais.

Seja partindo de textos já existentes, seja produzindo o material de análise a partir de entrevistas e observações, a pesquisa qualitativa pretende aprofundar a compreensão dos fenômenos que investiga a partir de uma análise rigorosa e 
criteriosa desse tipo de informação, isto é, não pretende testar hipóteses para comprová-las ou refutá-las ao final da pesquisa; a intenção é a compreensão (p. 191).

Desta forma, a pesquisa qualitativa nos dá condições de responder o problema proposto nesta pesquisa, à medida que buscamos compreender a contribuição da SEI na aprendizagem dos conteúdos de Botânica com professores em formação inicial no curso de Pedagogia.

Para Minayo (2002), pela pesquisa qualitativa não buscamos compreender a realidade por intermédio de dados quantificados, mas através de "[...] um universo de significados, motivos, aspirações, crenças, valores e atitudes, o que corresponde a um espaço mais profundo dos processos e dos fenômenos que não podem ser reduzidos à operacionalização de variáveis". Nesse sentido, a pesquisa qualitativa será utilizada para obtenção de dados mediante a fala dos participantes da investigação.

Participaram deste estudo 71 estudantes do Curso de Licenciatura em Pedagogia da UFAL, sendo 39 do turno diurno e 37 do turno noturno, matriculados na disciplina SMEC II. O desenvolvimento desta pesquisa converge com a resolução no 466/12 do Conselho Nacional de Saúde (BRASIL, 2012), responsável pela regulamentação de pesquisas que envolvem seres humanos. Assim, ressaltamos que todos os participantes tiveram sua integridade e anonimato assegurado. Para a coleta de dados e divulgação das informações todos os participantes assinaram o Termo de Consentimento Livre e Esclarecido (TCLE).

A coleta de dados, por sua vez, deu-se por meio da gravação em áudio, de desenhos e de textos produzidos pelos estudantes. Para a análise dos dados obtidos, optamos por analisar de forma qualitativa por meio da análise textual discursiva (ATD) as falas dos participantes da pesquisa e seus desenhos. Os textos produzidos não foram destacados nesta pesquisa. $\mathrm{O}$ fato da SEI ter sido aplicada em 3 turmas, uma em cada turno, nos fez optar por selecionar algumas falas em que os estudantes se mostram envolvidos nos momentos de discussão e que nos auxilia a alcançar o objetivo desta pesquisa. Com a finalidade de preservamos a identidade dos participantes desta pesquisa serão atribuídos números a cada futuro professor. Assim, os estudantes passam a ser identificados por A1, A2, A3 etc.

A aplicação da SEI ocorreu depois das discussões relacionadas à importância das atividades investigativas e da Alfabetização Científica ocorridas na disciplina SMEC II. Focalizamos analisar o material coletado por meio da ATD (MORAES, 2003; MORAES; GALIAZZI, 2016) na busca da produção de novos conhecimentos e 
entendimentos a respeito do fenômeno investigado. A ATD objetiva compreender o fenômeno investigado em sua totalidade. Sendo assim, compreendemos que mesmo na singularidade do campo investigado há uma totalidade.

A análise textual fundamenta-se em três fases: a unitarização, que é o momento de desconstrução dos dados de pesquisa, no qual podemos assumir as interpretações de forma unitária. Concluindo essa etapa, partimos para a segunda que é a categorização, um processo que não surge pronto: é construído por meio descobertas e redescobertas no momento de criação das categorias, podendo despontar diferentes níveis de categorias e subcategorias. A partir delas serão descritos e interpretados os dados analisados. A terceira e última fase é a comunicação na qual estão descritas as interpretações dos dados analisados (MORAES; GALIAZZI, 2016).

Desenvolver a análise dos dados coletados por meio da ATD contribui para a pesquisa em educação, sendo o pesquisador parte do processo de interpretação, na qual sua individualidade e conhecimentos são levados em consideração na interpretação dos dados.

\section{SEl: a estrutura das plantas e o nascimento da banana}

A SEI poderá ser realizada de acordo com a quantidade de aulas que o professor julgar necessário. Neste estudo, uma aula foi suficiente para trabalharmos os dois momentos da SEI, o que pode variar na Educação Básica, entre organizar a turma (em pequenos grupos de até 5 alunos), se fazer compreendido pelos estudantes e realizar todas as atividades. Sendo assim, o professor pode necessitar de mais aulas. O conteúdo a ser abordado neste estudo é Botânica.

Os materiais necessários são diferentes tipos de plantas. Buscando aproximar o conteúdo da realidade dos estudantes, optamos pelas seguintes plantas: goiabeira (PsidiumguajavaL) pertencente à família Myrtaceae; mangueira (Mangifera indica L) pertencente à família Anarcadiaceae; espada-de-são-jorge (Sansevieriatrifasciatalaurentii) pertencente à família Liliaceae; jambeiro (Syzygium jambos L.) pertencente à família Myrtaceae; bananeira (Musa spp) pertencente à família Musaceae e; o Cacto pertencente à família Cactaceae.

Ao realizarmos a SEI, objetivamos que os estudantes possam descrever as estruturas das plantas, buscando identificar suas similaridades e as diferenças; desenvolver a capacidade de argumentação por meio da observação; compreender 
que algumas estruturas são idênticas, porém se apresentam de forma diferente de acordo com a necessidade da planta; organizar e registrar informações por meio de desenhos e textos. Além disso, buscamos enfatizar aos futuros professores que o ensino das plantas pode ser trabalhado utilizando recursos que extrapolem o livro didático.

O planejamento da SEI está dividido em dois momentos, cada momento é composto por algumas etapas. Assim, inicialmente a SEI busca verificar o conhecimento inicial dos estudantes. Para isso, o professor necessita utilizar diferentes imagens de plantas, com cores, formatos e inseridas em diferentes ambientes. Caso o docente não disponha de aparelhos de projeção poderá utilizar imagens impressas.

Ao mostrar as diferentes plantas aos estudantes, o professor poderá fazer uso dos seguintes questionamentos: Todas as plantas são iguais? O que elas possuem em comum? O que elas apresentam de diferente? As plantas e os ambientes onde elas estão localizadas são iguais? Existe relação entre a estrutura da planta com o ambiente na qual ela está localizada? Torna-se importante atentar para as explicações fornecidas pelos estudantes.

Realizada essa primeira etapa, o professor distribuirá para cada grupo diferentes tipos de plantas e proporá aos discentes que busquem responder ao seguinte questionamento: Quais as estruturas que podemos identificar nessas plantas? Para a realização de cada etapa, é recomendável que os estudantes disponham de um tempo determinado pelo professor.

Finalizado essa etapa, o professor reúne os estudantes em um círculo para verificar se os estudantes conseguiram responder a pergunta. $\mathrm{O}$ professor pode utilizar as seguintes perguntas norteadoras: Quais foram as estruturas que vocês conseguiram observar nas plantas? Todas as estruturas eram iguais? O que elas possuíam de diferente? As folhas são iguais? Quais as estruturas presentes no cacto? $\mathrm{O}$ cacto possui folha? E as raízes? Todas possuem o mesmo formato? As perguntas podem ser adaptadas assim como novas perguntas podem surgir mediante as argumentações dos estudantes.

Posteriormente a este momento que possui como foco central o desenvolvimento de explicações por meio das observações, são realizadas algumas atividades, como objetivo de sistematização do conhecimento. A atividade a seguir busca fazer com que os estudantes completem a poesia relacionando a estrutura das plantas a sua função. 
: Do mundo não vejo nada, pois vivo sempre enterrada, mas não me entristeço, não, seguro a planta e a sustento sugando água e alimento.

: Sou tronco que levanta e estende para os espaços braços, braços e braços colhendo a luz para a planta.

Da planta sou o pulmão, mas além de respirar, tenho uma grande função: Roubo energia solar.

: Sou a mãe da vegetação e me perfumo e me enfeito para criar em meu peito plantinhas que nascerão.

: Sou o cálice da flor, que inchou e ficou maduro pela força do calor e guardo em mim, com amor, as plantinhas do futuro.

Atividade Disponível em:http://peregrinacultural.wordpress.com/2008/07/26/ historia-da-planta-poesia-infantil-de-ofelia-e-narbal-fontes/

A próxima atividade propõe aos estudantes que escolham algumas das espécies de plantas observadas durante a aula e desenhem suas estruturas. Para isso elaboramos uma tabela, onde deverá ser identificada a planta pelo nome, o desenho da folha, raiz e caule.

\section{Tabela 1}

\begin{tabular}{c|c|c|c}
\hline Planta (nome) & Folha & Raiz & Caule \\
\hline & & & \\
\hline
\end{tabular}

Fonte: autor)

Como forma de contribuir também com o desenvolvimento da leitura dos estudantes, o professor pode sugerir que seja feita a leitura de um texto que aborde a temática da aula. Para essa sequência utilizamos o texto sobre o ciclo de vida das plantas disponível em :https://super.abril.com.br/mundo-estranho/a-infancia-a-adolescencia-e-a-velhice-das-plantas/. E para finalizar esse primeiro momento, foi solicitado aos estudantes que escrevessem um texto sobre o que aprenderam durante a aula.

O segundo momento da SEI trata do nascimento do fruto, mais especificamente do nascimento da banana, portanto, esse momento recebe o nome de "nem todo fruto nasce da semente?" Como destacado anteriormente, a quantidade de aulas para realização desse momento vai de acordo com a realidade de cada sala de aula. Para sua execução, necessitamos de alguns tipos de frutas, de modo que utilizamos nessa SEI: mamão, goiaba, maracujá, banana e laranja. A primeira etapa consistiu 
em entregar para os grupos os diferentes tipos de frutas cortadas e questionar o que elas possuíam em comum.

Outros questionamentos feitos foram sobre o que precisamos fazer caso necessitemos plantar uma laranjeira, um mamoeiro ou uma goiabeira, e caso desejássemos plantar uma bananeira o que deveria ser feito? Esse momento é marcado pela dúvida se a banana possui ou não semente e o que seriam aquelas estruturas pretas dentro da banana. Realizado esse momento, o professor pode utilizar um texto, ou vídeo para que os estudantes possam compreender como nasce uma banana se ela não tem semente. $O$ texto escolhido foi "de onde vêm as bananas se elas não têm sementes”, disponível no site:https://www.dgabc.com.br/Noticia/1811904/de-onde-vem-as-bananas-se-elas-nao-tem-sementes.

Após a leitura do texto realizada pelos estudantes, buscamos verificar se os estudantes conseguiram compreender se de fato a banana possui ou não semente e o que são aquelas estruturas presentes na banana. A sistematização do conhecimento ocorreu mediante a exposição do desenho Show da Luna no episódio "nem tudo nasce da semente?" Disponível no site: https://www.youtube.com/watch?v=0nMmWgETnMY. Para finalizar esse momento o docente pode solicitar aos estudantes que exercitem a escrita produzindo um texto sobre o que aprenderam na aula.

\section{Resultados e discussão}

\section{Primeiro momento}

O primeiro momento busca destacar as discussões que ocorreram após os estudantes observarem os cinco tipos de plantas utilizadas na SEI, já descrita anteriormente, momento no qual tínhamos como objetivo identificar as estruturas de cada planta, além das suas semelhanças e diferenças.

A seguir apresentaremos resultados e discussões a respeito das concepções apresentadas pelos estudantes. Neste momento é solicitado aos grupos que exponham as estruturas das plantas que conseguiram identificar.

As plantas observadas possuem folhas, raiz (umas são mais grossas, outras são mais finas) algumas folhas são largas, alguns caules são finos outros grossos, a espada-de-são-jorge não possui caule, apenas folha, uma folha grossa (A12-turno matutino). 
A maioria das plantas possui folha, raiz, caule. Os formatos das raízes são diferentes, a mangueira possui um caule, caule e tronco é a mesma coisa? O tamanho da folha é diferente. A folha da espada-de-são-jorge é diferente da mangueira. As raízes possuem formatos diferentes, algumas são mais superficiais (A16-turno vespertino).

As plantas possuem algumas partes que se repetem, mas que são diferentes. A espada-de-são-jorge possui uma folha comprida e tem essa diferencia de cores (A22-turno noturno).

As falas dos estudantes trazem informações importantes a partir de suas observações, a aproximação entre os discentes e seu objeto de estudo não restringe apenas a nomeação. Os estudantes passam a estabelecer relações entre tamanho, formato e texturas que estão presentes nos diferentes tipos de plantas. É possível observar que os discentes passam a tomar consciência que a maioria das estruturas estão presentes em todas as plantas observadas, mas que possuem morfologias distintas.

Quando os estudantes foram questionados sobre quais eram as estruturas do cacto, responderam que:

Não possui folhas, foi adaptada para o espinho, porque a folha precisa de água. (alunos sorriem da explicação da aluna) (A2-turno matutino).

É uma planta característica do sertão, não precisa de muita água, tem espinho que é uma característica do cacto e tem raízes. O cacto está em região quente, o colega aí falou que o cacto absorve água, mas como ele absorve água se no sertão passa uns quatro a cinco meses sem chover, de onde vem essa água? (A18-turno vespertino).

Diante desse questionamento, o professor questiona se alguém poderia ajudar o colega diante dessa dúvida, um dos estudantes responde:

Será que a raiz do cacto é profunda justamente para ele absorver água por essa questão levantada pelos colegas do tempo sem água? (A5-turno matutino).

O discente levanta uma hipótese na tentativa de fornecer respostas ao questionamento do colega. Para Sasseron e Carvalho (2008, p 339) "este levantamento de hipótese pode surgir tanto na forma de uma afirmação como sendo uma pergunta (atitude muito usada entre os cientistas quando se defrontam com um problema)". O levantamento de hipóteses se constitui como uma das habilidades que os estudantes precisam desenvolver no ensino de Ciências e que por meio do Ensino por Investigação pode ser potencializada.

Ainda na discussão sobre os cactos, nos turnos vespertino e noturno os estudantes afirmam que: 
O cacto é diferente das outras, não tem folha, tem espinho. E o cacto tem raiz e não tem caule. Eu não sei se essa parte verde é caule ou folha. Professor, eu falo que têm folha porque lá no interior diz: olha vai cortar umas folhas da palma. Acho que ele extrai água do subsolo, por isso que esse tipo de planta é para qualquer região, por isso que papai do céu fez essas plantas para lá (ambiente seco). Os espinhos são para defesa contra insetos. Ele possui raiz, o caule (parte verde) e os espinhos, os espinhos também dão flores (A19-vespertino).

São uns tipos de planta que não possui folhas, apenas espinhos (A23-noturno).

Nas falas de A19 e A23 para fornecer explicações ao descrever as estruturas das plantas recorre a um conhecimento que já possuem construído por meio de suas experiências do cotidiano, anterior a aula. Desta forma, se reafirma a importância dos conhecimentos prévios que os estudantes possuem, e na falta de argumento científico para explicar o fenômeno, o estudante recorre à religião para fornecer explicações.

Essa situação se torna importante porque converge com o que é apontado por Carvalho (2013). Para a autora, com embasamento nas ideias de Piaget, quando os estudantes se deparam com problemas em que o conhecimento que possuem não dão condições de dar resposta à pergunta problema ocorre um desequilíbrio cognitivo e na busca por tentar responder ao problema proposto ocorre o reequilíbrio na aprendizagem. Desta forma, a implementação do Ensino por Investigação torna a sala de aula um ambiente investigativo, pautado na discussão, elaboração de argumentos e interação.

Ao serem questionados se todas as raízes eram iguais destacamos o seguinte trecho:

Os formatos das raízes são diferentes, A cenoura que é uma raiz concentra nessa região aqui (estudante aponta para a estrutura) que é comestível (A14-turno matutino).

Diante dessa explicação, o professor busca saber o motivo pelo qual podemos ingerir a cenoura que é uma raiz e não podemos ingerir, por exemplo, a raiz da mangueira, as respostas obtidas foram as seguintes:

Porque a raiz da cenoura foi feita para a gente comer. Essa raiz ela absorve nutriente $e$ eles ficam concentrados e serve de alimento para nós. E a mangueira leva o nutriente para os frutos (A13-turno matutino).

A cenoura é comestível e essa não é (aponta para outra planta). Agora eu não consigo explicar porque uma raiz é comestível e outras não. A cenoura é uma verdura (A20- turno vespertino). 
A resposta dos estudantes para o questionamento revela que por meio da observação os estudantes vão além do que é questionado, estabelecendo relação entre a estrutura da planta e a sua função, destacando a raiz como a responsável por absorver e transportar nutrientes para a planta. Os estudantes seguem descrevendo suas observações sobre as raízes

As raízes da mangueira são maiores porque a planta cresce muito e são mais grossas porque a planta vai precisar de mais nutriente, por isso ela necessita de uma raiz mais grossa. (A7-turno matutino).

As raízes são diferentes, algumas finas. A raiz da bananeira é mais resistente que as outras. Professor, a gente tinha entrado em discussão de que a bananeira só dá banana uma vez, eu lembro que meu pai não chegava a plantar uma outra bananeira, quando cortava uma já nascia outra, eu não sei se raiz forma outra bananeira" (A15-turno vespertino).

Diante das falas observadas no primeiro momento, a argumentação é uma característica que emerge durante toda aula. Para Sasseron (2015) os argumentos vão além de um simples diálogo, mas demonstram a organização do pensamento, seja pela fala, escrita ou registros gráficos. Tal situação pode ser compreendida ao observamos os desenhos produzidos pelos estudantes.

\section{Figura 1:}

\begin{tabular}{|c|c|c|c|}
\hline & Fothe & coulo \\
\hline & & & \\
\hline
\end{tabular}

Fonte: Arquivo pessoal.

Diante desse registro gráfico, compreendemos que por meio da observação direcionada os estudantes ao desenharem, descrevem característica das plantas que não foram destacadas em suas falas, como por exemplo a disposição das nervuras das folhas que são diferentes em cada espécie de planta. O caule da espada-de-são-jorge 
(segunda planta) se mostra diferente das demais, sendo um caule do tipo rizoma com a presença de raízes adventícias. Já o caule da bananeira é retratado como folhas.

Portanto, neste primeiro momento, percebemos que os futuros professores, por meio das atividades investigativas e das discussões realizadas, identificaram a estrutura das plantas e suas semelhanças e diferenças.

\section{Segundo momento}

Esse momento corresponde à segunda parte da SEI, tendo como objetivo conhecer as concepções que os estudantes possuem para o nascimento do fruto, evidenciando o nascimento da banana. Assim, após mostrar uma série de frutas que possuem sementes, o professor questiona se as bananas possuem sementes. Nos turnos onde a pesquisa foi realizada é possível verificar que os estudantes apresentam divergências em suas concepções enquanto a existência ou não da semente da banana.

O diálogo estabelecido entre os estudantes demonstra que o planejamento desta SEI possui como foco central a participação ativa dos estudantes. O professor, à medida que os argumentos vão sendo desenvolvidos, atua como um propositor de questão, como podemos verificar neste trecho: "então, já que alguns de vocês falaram que a banana não possui semente o que a gente precisa fazer se quisermos plantar uma bananeira?”. O docente precisar estar atento para a forma como as discussões serão conduzidas, buscando não dar respostas para os estudantes, mas orientando de acordo com os argumentos estabelecidos pelos discentes com novas formas de raciocinar e refletir sobre o assunto discutido (SASSERON, 2015).

Outro ponto a ser destacado é que os estudantes passam a levantar hipóteses na tentativa de dar respostas à questão ao destacarem que se quisermos plantar uma bananeira podemos utilizar "a casca, planta o filhotinho, caule" (A9, A10 e A11). Outro ponto a ser mencionado é a valorização dos conteúdos atitudinais, pois embora os estudantes, na maioria das vezes, não concordem com a opinião estabelecida entre os colegas, buscam respeitar as diferenças de pensamento.

No Ensino por Investigação existe consenso no que se refere a essa perspectiva proporcionar ao aluno aprendizagem de conceitos, atitudes, procedimentos, desenvolvimento de diversas habilidades cognitivas e a compreensão da natureza da ciência (ZÔMPERO; LABURÚ, 2011). Assim, notamos que além das questões propostas pelo professor, os estudantes também propõem novas questões que podem 
levar a diferentes discussões, fato observado quando na aula foi discutido sobre o nascimento da banana e o estudante questiona: "e o coco então?". Perguntas como essa pode ser respondida a partir de uma pesquisa, não necessariamente o professor deve dar a resposta.

\section{Considerações finais}

A utilização do Ensino de Ciências por Investigação para trabalhar conteúdos científicos na sala de aula se torna uma importante estratégia didática, que possui potencialidades para auxiliar a prática docente no desenvolvimento de aulas que saiam do senso comum pedagógico sobre como ensinar Ciências. Pois, se almejamos tornar os estudantes capazes de atuarem na sociedade tendo a possibilidade de transformá-la é necessário rompermos com um ensino baseado exclusivamente na exposição do conteúdo e no livro didático, distante da realidade dos estudantes, reverberando no desinteresse discente.

A execução da SEI com estudantes do curso de Licenciatura em Pedagogia demonstrou que embora estejamos lhe dando com um público que já dispõe de um conjunto de conhecimento que são resultantes de suas experiências ao longo do processo formativo por meio da Educação Básica, possuem dificuldades em estabelecer explicações aceitas cientificamente. Entretanto, não lhes impedem de utilizar seus conhecimentos construídos também fora da escola para tentar explicar suas observações.

Ao passo que a utilização do Ensino por Investigação conduz os estudantes a se apropriarem do conhecimento de maneira diferente do ensino considerado como tradicional, é a argumentação desenvolvida por meio da observação um dos principais benefícios promovido por essa estratégia didática. Ao partimos do pressuposto de que é necessário que os estudantes saibam se comunicar/argumentar em Ciências, a SEI utilizada para trabalhar conteúdos de Botânica assume particular relevância para o desenvolvimento desta habilidade.

Embora um único integrante de um grupo tenha destacado dificuldades de compreender as atividades presentes na SEI, o que poderia afetar a compreensão de seus estudantes, buscamos adequar a linguagem da SEI para trabalhar com crianças dos anos iniciais do Ensino Fundamental. Outra dificuldade que precisa ser destacada é a quantidade de atividades presentes na SEI, que pode inviabilizar 
o professor de concluir no tempo de aula. Em nosso caso, mesmo a SEI possuindo dois momentos, ambos não possuem ligação podendo ser executados em diferentes tempos.

A forma utilizada pelos estudantes para explicar alguns questionamentos durante as atividades se assemelham as falas das crianças ao tentar dar explicação para o que conhecem, porém não sabem nomear cientificamente. Ao passo que, a interação e o desenvolvimento da atitude de ouvir os demais estudantes, auxilia na compreensão da sua dúvida sobre determinadas estruturas das plantas.

Esta pesquisa se propôs a contribuir com a formação de professores dos anos iniciais, em particular dos futuros pedagogos da Universidade Federal de Alagoas, despertando a compreensão sobre a importância da diversificação metodológica, tendo no ensino por investigação um auxílio para o desenvolvimento de aulas de Ciências baseadas em características do trabalho científico. Faz-se necessário que o docente busque considerar seus futuros estudantes como capazes de estarem inseridos em momentos de investigação, desenvolvendo habilidades científicas que podem ser potencializadas ao longo do seu processo formativo, contribuindo com a Alfabetização Científica.

O desenvolvimento e execução de uma SEI com conteúdo sobre as plantas demonstra a necessidade desses conteúdos serem trabalhados desde os anos iniciais de forma que busque inserir os estudantes em momentos de argumentação e reflexão, para que desde cedo possam compreender a importância destes organismos para existência da vida no planeta. Tal compreensão pode se tornar fragilizada a medida em que nas poucas aulas de Ciências presente nestes níveis escolares esteja baseada na repetição de informações presente nos livros didáticos e na exposição do conteúdo.

Espera-se que por meio desta pesquisa possamos despertar outros estudos que venham abordar a necessidade de contribuirmos com a prática docente destes profissionais; que se produzam recursos pedagógicos que possam ser reproduzidos pelos professores na Educação Básica e que possam ser adaptados à realidade de cada um. Como as atividades que compõe a SEI presente nesta pesquisa, utilizando materiais próximos do contexto dos professores e estudantes e que auxiliam na construção do conhecimento. 


\section{Agradecimentos}

O presente trabalho foi realizado com apoio da Fundação de Amparo à Pesquisa do Estado de Alagoas - FAPEAL e com apoio da Coordenação de Aperfeiçoamento de Pessoal de Nível Superior - Brasil (CAPES) - Código de Financiamento 001.

\section{Science Teaching by Research: A Didactic Strategy to Assist the Practice of Teachers in the Early Years of Elementary School}

\section{Abstract}

Teaching science so that students can (re) build their understanding of the world around them through the language of science requires the teacher to reflect on the didactic strategies used for this purpose. In this context, we highlight the potentialities that Teaching by Investigation can assume in face of this educational need. Thus, we developed a research-basedteachingsequence $(\underline{\underline{R T S}})$ to work on two Botany contents in order to investigate the contributions of this didactic strategy to the learning of teachers in the early years of elementary school. This study aimed to verify how the participants' learning process occurred after the application of RTS; identify the suggestions of these future teachers for its adaptation and improvement and describe the potential of this didactic strategy to work content of biological nature. The research was developed in the discipline of Knowledge and Methodology of Science Teaching II. This course is part of the curriculum matrix of the Degree in Pedagogy at the Federal University of Alagoas. Thus, this research has a qualitative approach, where we seek to analyze the dialogues recorded through audio recording. In this context we chose to perform discursive textual analysis. As a result, we find that teachers in initial education have difficulties in providing explanations based on scientific knowledge. We also realize that the use of RTS can make the classroom a dialogical environment of discovery and reconstruction of existing knowledge, becoming an important didactic strategy for working scientific knowledge at all levels of education.

Keywords: Initial Teacher Formation. Science teaching. Didactic strategy. Botany Contents.

\section{Referências}

AUGUSTO, Thaís Gimenez da Silva; AMARAL, Ivan Amorosino do. A formação de professoras para o ensino de ciências nas séries iniciais: análise dos efeitos de uma proposta inovadora. Ciência \& Educação (Bauru), 2015, 21.2: 493-509

BIZZO, Nélio Marco Vincenzo. Ciência: fácil ou difícil? 2009.

BONANDO, P. A. Ensino de Ciências nas séries iniciais do $1^{\circ}$ grau-descrição e análise de um programa de ensino e assessoria ao professor. UFSCar (Dissertação de Mestrado), 1994. 
BOSZKO, C.; DA COSTA GÜLLICH, R. Estratégias de ensino de ciências e a promoção do pensamento crítico em contexto brasileiro. Revista Brasileira de Ensino de Ciências e Matemática, v. 2, n. 1, p. 53-71, 16 ago. 2019.

BRASIL. Parâmetros curriculares nacionais. Brasília, DF: MEC / SEF. 1997.

Base Nacional Comum Curricular. Brasília: MEC, 2017. Disponível em: http://basenacionalcomum.mec.gov.br/images/BNC C_20dez_site.pdf. Acesso em: 18 de novembro de 2017.

. Base Nacional Comum Curricular: Ensino Médio. Brasília, Df. 2018.

. Resolução CNS/MS №. 466/12 que regulamenta diretrizes e normas regulamentadoras de pesquisas envolvendo seres humanos. Diário Oficial da União, Brasília: CNS, 2012.

CARVALHO, Anna Maria Pessoa de et al. Ensino de Ciências por investigação: condições para implementação em sala de aula. São Paulo: cengagelearning, 2013, 1-20.

CARVALHO, Anna Maria Pessoa de. Ensino e aprendizagem de Ciências: referenciais teóricos e dados empíricos das sequências de ensino investigativas-(SEI). $O$ uno e o diverso na educação, 2011

CHASSOT, Attico. Alfabetização científica: questões e desafios para a educação. Unijuí, 2018.

GALIAN, Cláudia Assumpção; ARROIO, Agnaldo; SASSERON, Lúcia Helena. Formação Inicial de Professores para o Ensino Fundamental I: o Conhecimento das Ciências Naturais no Currículo do Curso de Pedagogia. Educação em Perspectiva, 2013.

GATTI, Bernadette; DE SÁ BARRETTO, Elba Siqueira. Professores do Brasil: impasses e desafios. Unesco Representação no Brasil, 2009.

GÜLLICH, Roque Ismael da Costa. A Botânica e seu ensino: história, concepções e currículo. 2003.

HOEHNE, F. C. Programa instructivo e educativo. Resenha Historica, 1937, 67-82.

KINOSHITA, Luiza Sumiko, et al. (ed.). A botânica no ensino básico: relatos de uma experiência transformadora. RiMa, 2006.

KRASILCHIK, Myriam. Prática de ensino de biologia. EdUSP, 2004.

LIMA, Maria Emilia Caixeta de Castro; MAUÉS, Ely. Uma releitura do papel da professora das séries iniciais no desenvolvimento e aprendizagem de ciências das crianças. Ensaio Pesquisa em Educação em Ciências (Belo Horizonte), 2006, 8.2: 184-198.

LONGHINI, Marcos Daniel. O conhecimento do conteúdo científico e a formação do professor das séries iniciais do ensino fundamental. Investigações em Ensino de Ciências, 2016, 13.2: 241-253.

LORENZETTI, Leonir; DELIZOICOV, Demétrio. Alfabetização científica no contexto das séries iniciais. Ensaio Pesquisa em educação em Ciências, 2001, 3.1: 1-17.

MARTINS, C. M. C.; BRAGA, S. A. M. As idéias dos estudantes, o ensino de biologia vegetal e o vestibular da UFMG. Encontro nacional de pesquisa em educação em ciências, 1999, 2: 1-11.

MAYR, Ernst. O desenvolvimento do pensamento biológico: diversidade, evolução e herança. Ed. UnB, 1998. 
MINAYO, M. C. Pesquisa social: teoria e método. Ciênica, Técnica, 2002.

MORAES, R.; GALLIAZI, M. C. Análise Textual Discursiva. 3 ed. rev. e ampl. Ijuí: Ed. Unijuí, 2016. 264p.

MORAES, Roque. Uma tempestade de luz: a compreensão possibilitada pela análise textual discursiva. Ciência \& Educação, 2003, 9.2: 191-211

OVIGLI, Daniel Fernando B.; BERTUCCI, Monike Cristina S. A formação para o ensino de ciências naturais nos currículos de pedagogia das instituições públicas de ensino superior paulistas. Ciências \& Cognição, 2009, 14.2.

Parecer CNE/CP 2 de 2015. Diretrizes Curriculares Nacionais para a Formação Inicial e Continuada dos Profissionais do Magistério da Educação Básica. Ministério da Educação. Aprovado em: 9/6/2015. Recuperado de http://portal.mec.gov.br/index.php?option=com_docman\&view=download\&alias=70431-res-cne-cp-002-03072015-pdf\&category_slug=agosto-2017-pdf\&Itemid=30192. 2015 .

PIRES, Elocir Aparecida Corrêa; MALACARNE, Vilmar. A formação do professor de Ciências para os anos iniciais do Ensino Fundamental. Acta Scientiae, 2016, 18.

ROCHA, Maína Bertagna. A formação dos saberes sobre ciências e seu ensino: trajetórias de professores dos anos iniciais do ensino fundamental. 2013. 265f. 2013. PhD Thesis. Tese (Doutorado em Educação)-Faculdade de Educação, Universidade Estadual de Campinas, Campinas, SP.

SANTANA, Isabel Cristina Higino; SILVEIRA, Andréa Pereira. Ensino de Ciências para a Formação do Pedagogo: Concepções de Alunos em Formação. Acta Scientiae, 2018, 20.5.

SANTOS, Deborah Yara Alves Cursino dos; CECCANTINI, Gregório Cardoso Tápias. Propostas para o ensino de botânica: manual do curso para atualização de professores dos ensinos fundamentais e médios. 2004.

SASSERON, Lúcia Helena. Alfabetização científica, ensino por investigação e argumentação: relações entre ciências da natureza e escola. Ensaio Pesquisa em Educação em Ciências (Belo Horizonte), 2015, 17.spe: 49-67.

SASSERON, Lúcia Helena; DE CARVALHO, Ana Maria Pessoa. Almejando a alfabetização científica no ensino fundamental: a proposição e a procura de indicadores do processo. Investigações em ensino de ciências, 2008, 13.3: 333-352.

Scarpa, D. L., \& Silva, B. M. A Biologia e o ensino de Ciências por investigação: dificuldades e possibilidades. In: Ensino de Ciências por Investigação: Condições para implementação em sala de aula. 2013

SILVA, Kelly Cristina Ducatti da. A formação no curso de Pedagogia para o ensino de ciências nas séries iniciais. 2005.

SOUZA, Ana Lúcia Santos; CHAPANI, Daisi Teresinha. Necessidades formativas dos professores que ensinam ciências nos anos iniciais. Práxis Educacional, 2015, 11.19: 119-136.

TRIVELATO, Sílvia L. Frateschi; TONIDANDEL, Sandra M. Rudella. Ensino por investigação: eixos organizadores para sequências de ensino de biologia. Ensaio Pesquisa em Educação em Ciências, 2015, 17: 97-114. 
URSI, Suzana, et al. Ensino de Botânica: conhecimento e encantamento na educação científica. Estudos Avançados, 2018, 32.94: 7-24.

WANDERSEE, James H.; SCHUSSLER, Elisabeth E. Toward a theoryofplantblindness. Plant Science Bulletin, 2001, 47.1: 2-9.

ZANON, Dulcimeire Aparecida Volante. Ensinar e aprender Ciências no ensino fundamental com atividades investigativas: enfoque no projeto $\mathrm{ABC}$ na Educação Científica Mão na Massa. 2005. PhD Thesis. Tese (Doutorado)-Faculdade de Educação, Universidade Federal de São Carlos, São Carlos, São Paulo.

ZÔMPERO, Andreia Freitas; LABURÚ, Carlos Eduardo. Atividades investigativas no ensino de ciências: aspectos históricos e diferentes abordagens. Ensaio Pesquisa em Educação em Ciências, 2011, 13.3: 67-80. 